\title{
Nutrient requirements and evaluation of equations to predict chemical body composition of dairy crossbred steers
}

\author{
Flávia Adriane de Sales Silva ${ }^{1, \star}$, Sebastião de Campos Valadares Filho ${ }^{1}$, Luiz Fernando Costa e Silva ${ }^{2}$, \\ Jaqueline Gonçalves Fernandes ${ }^{3}$, Bruno Corrêa Lage ${ }^{1}$, Mario Luiz Chizzotti ${ }^{1}$, and Tara Louise Felix ${ }^{4}$
}

\author{
* Corresponding Author: \\ Flávia Adriane de Sales Silva \\ Tel: +55-31-3612-4648, Fax: +55-31-3612-4648, \\ E-mail: flavia.sales@ufv.br \\ ${ }^{1}$ Department of Animal Science, Universidade \\ Federal de Viçosa, Viçosa 36570-900, Brazil \\ ${ }^{2}$ Alltech do Brasil Agroindustrial, Maringá \\ 87050220, Brazil \\ ${ }^{3}$ Department of Statistics, Universidade \\ Federal de Lavras, Lavras 37200-000, Brazil \\ ${ }^{4}$ Department of Animal Science, Pennsylvania \\ State University, University Park, State \\ College, PA 16802, USA \\ ORCID \\ Flávia Adriane de Sales Silva \\ https://orcid.org/0000-0001-5819-5638 \\ Sebastião de Campos Valadares Filho \\ https://orcid.org/0000-0003-4544-6316 \\ Luiz Fernando Costa e Silva \\ https://orcid.org/0000-0002-4107-0932 \\ Jaqueline Gonçalves Fernandes \\ https://orcid.org/0000-0002-7236-9718 \\ Bruno Corrêa Lage \\ https://orcid.org/0000-0001-8451-8955 \\ Mario Luiz Chizzotti \\ https://orcid.org/0000-0001-9770-6891 \\ Tara Louise Felix \\ https://orcid.org/0000-0001-6263-180X
}

Submitted Oct 22, 2019; Revised Mar 5, 2020; Accepted Jun 16, 2020
Objective: Objectives were to estimate energy and protein requirements of dairy crossbred steers, as well as to evaluate equations previously described in the literature (HH46 and CS16) to predict the carcass and empty body chemical composition of crossbred dairy cattle.

Methods: Thirty-three Holstein $\times$ Zebu steers, aged $19 \pm 1$ months old, with an initial shrunk body weight (BW) of $324 \pm 7.7 \mathrm{~kg}$, were randomly divided into three groups: reference group $(\mathrm{n}=5)$, maintenance level $(1.17 \% \mathrm{BW} ; \mathrm{n}=4)$, and the remaining 24 steers were randomly allocated to 1 of 4 treatments. Treatments were: intake restricted to $85 \%$ of ad libitum feed intake for either $0,28,42$, or $84 \mathrm{~d}$ of an 84-d finishing period.

Results: The net energy and the metabolizable protein requirements for maintenance were $0.083 \mathrm{Mcal} / \mathrm{EBW}^{\mathrm{d}} / \mathrm{d} / \mathrm{d}$ and $4.40 \mathrm{~g} / \mathrm{EBW}^{0.75}$, respectively. The net energy $\left(\mathrm{NE}_{\mathrm{G}}\right)$ and protein $\left(\mathrm{NP}_{\mathrm{G}}\right)$ requirements for growth can be estimated with the following equations: $\mathrm{NE}_{\mathrm{G}}(\mathrm{Mcal} / \mathrm{kg} \mathrm{EBG})=0.2973_{( \pm 0.1212)} \times E B W^{0.4336_{( \pm 0.1002)}}$ and $\mathrm{NP}_{\mathrm{G}}(\mathrm{g} / \mathrm{d})=183.6_{( \pm 22.5333)} \times \mathrm{EBG}-$ $2.0693_{( \pm 4.7254)} \times \mathrm{RE}$, where EBW, empty BW; EBG, empty body gain; and RE, retained energy. Crude protein $(\mathrm{CP})$ and ether extract (EE) chemical contents in carcass, and all the chemical components in the empty body were precisely and accurately estimated by CS16 equations. However, water content in carcass was better predicted by HH46 equation.

Conclusion: The equations proposed in this study can be used for estimating the energy and protein requirements of crossbred dairy steers. The CS16 equations were the best estimator for $\mathrm{CP}$ and $\mathrm{EE}$ chemical contents in carcass, and all chemical components in the empty body of crossbred dairy steers, whereas water in carcass was better estimated using the HH46 equations.

Keywords: Carcass Composition; Cattle; Body Composition

\section{INTRODUCTION}

It is recognized that dairy (Holstein and Holstein crossbreeds) and beef cattle exhibit differences regarding their nutritional requirements [1,2]. However, despite the large participation of male dairy cattle in feedlots in US and Brazil [3-5], most of nutritionists in US (92.2\%) and Brazil (71.7\%) use some version beef cattle NRC as source of information on nutrient requirements to formulate diets $[3,6]$. Therefore, the establishment of proper nutritional requirements for male dairy cattle and its crossbreeds is necessary and consequently ensures their subsequent productive performance and farmers profitability.

In this regard, quantifying body composition is a major obstacle when estimating nutrient requirements. The direct determination of body composition, which is based on the separation and dissection of all body constituents, and analysis of its individual constituents, is the most accurate method available, to generate reliable data. However, this process is 
lengthy, laborious, and expensive. Due to these challenges, indirect methods have been developed for estimating body composition [7-9].

Among the indirect methods available, the method that predicts body composition from equations based on the 9th to 11th rib section composition, which was first proposed by Hankins and Howe (HH46) [7], is wide spread due the ease of use, reduced cost involved, and speed of the process. However, Paulino et al [10] and Marcondes et al [11] unanimously concluded that the equations developed by HH46 [7] were not fully applicable to predict body composition of Zebu cattle. Prediction equations to estimate the growth pattern and composition of gain of Holstein $\times$ Zebu crossbreds have not been reported. In this respect, Costa e Silva et al (CS16) [2] developed equations for estimating body composition of crossbred dairy cattle. Nonetheless, they still need to be evaluated with an independent database in order to be widely and reliably adopted. Therefore, testing those equations for crossbred dairy animals should provide useful information about their utility for such animals. Thus, the objectives were to estimate energy and protein requirements of dairy crossbred steers, as well as to evaluate the goodness of fit of prediction equations developed by HH46 [7] and CS16 [12] to predict the carcass and empty body chemical composition of crossbred dairy cattle.

\section{MATERIALS AND METHODS}

The animal care and use committee of the Universidade Federal de Viçosa approved all procedures involving animals (protocol number 12/2016).

Location, animals resource, study design, diet, and feed composition

Thirty-three $3 / 4$ Holstein $\times$ Zebu steers (average age $=19 \pm 1$ months; average initial body weight $[\mathrm{BW}]=324 \pm 7.7 \mathrm{~kg}$ ) were used in this study. Gyr was the Zebu breed utilized in the crossbreeding. Five steers were assigned to a baseline group (BW $=341 \pm 21.1), 4$ were fed at maintenance $(1.17 \%$ $\mathrm{BW}$; $\mathrm{BW}=328 \pm 23.6)$, whereas 24 steers $(\mathrm{BW}=320 \pm 8.3$ ) were randomly allotted to 1 of 4 treatments ( $n=6$ steers per treatment). Treatments were: intake restricted at $85 \%$ of ad libitum dry matter (DM) for 0 (R0) or no restriction, 28 (R28), 42 (R42), or 84 (R84) d of an 84-d finishing period. These strategies were needed to obtain sufficient variation in the body composition to mimic animal growth patterns.

The steers were housed in $6 \mathrm{~m}^{2}$ individual pens with a concrete floor, which were equipped with individual feeders and continuous flow concrete drinkers. The experimental diet was the same for all treatments. The diet was calculated according to BR CORTE recommendations [2] to provide approximately $11 \%$ crude protein $(\mathrm{CP})$ on a DM basis and to support an average daily gain (ADG) of $1.4 \mathrm{~kg}$. The diet contained (DM basis) $40 \%$ corn silage and $60 \%$ of a concentrate mix (Table 1).

The feed was provided once a day $(0800 \mathrm{~h})$ as total mixed ration, and the steers had free access to clean water. The diet for R0 steers was adjusted daily to provide orts of approximately $2 \%$ (as fed basis) of the total offered, and orts were mixed with the new feed that was offered in the next day. Briefly, bunks were evaluated at $0700 \mathrm{~h}$ daily to quantify refusals. According to the amount of refusals, the total mixed ration was reduced (more than $2 \%$ orts at morning evaluation) or increased (less than $2 \%$ orts at morning evaluation) to reach ad libitum intake. Silage was sampled daily and stored at $-20^{\circ} \mathrm{C}$ until further analysis. Silage samples were combined weekly (percent as-fed basis), dried in a forced-air oven $\left(55^{\circ} \mathrm{C}\right)$ for $72 \mathrm{~h}$, and ground through a 1-mm screen (Fortinox, Piracicaba, SP, Brazil). The individual ingredients used to prepare the concentrate were sampled directly from the feed mill silos on the days the concentrate was mixed. These ingredients were analyzed individually and used to calculate the diet composition.

Digestibility trials, slaughter and sampling procedures To evaluate apparent total-tract digestibility and consequently the total digestible nutrients (TDN), two digestibility trials were performed, from d 25 to 27 and d 73 to 75 , by collect-

Table 1. Composition of experimental diet

\begin{tabular}{lc}
\hline Item & \% Dry matter \\
\hline Diet composition & \\
Corn silage & 40.0 \\
Ground corn & 53.6 \\
Soybean meal & 3.60 \\
Urea & 0.90 \\
Ammonium sulfate & 0.10 \\
Sodium bicarbonate & 0.75 \\
Magnesium oxide & 0.25 \\
Mineral mixture & 0.13 \\
Salt & 0.30 \\
Limestone & 0.42 \\
Analyzed composition & \\
Dry matter & 43.5 \\
Organic matter & 94.2 \\
Crude protein & 11.0 \\
Ether extract & 2.95 \\
Neutral detergent fiber ${ }^{2)}$ & 27.6 \\
Non-fiber carbohydrates & 54.3 \\
Energy density (Mcal/kg DM) & \\
$N_{M}$ & 1.91 \\
NE &
\end{tabular}

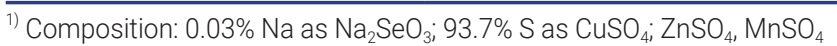
and $\mathrm{CoSO}_{4} ; 0.48 \% \mathrm{Cu}$ as $\mathrm{CuSO}_{4} ; 4.71 \% \mathrm{Zn}$ as $\mathrm{ZnSO}_{4} ; 0.77 \% \mathrm{Mn}^{2} \mathrm{MnSO}_{4}$; $0.06 \% \mathrm{Se}$ as $\mathrm{Na}_{2} \mathrm{SeO}_{3} ; 0.25 \%$ Co as $\mathrm{CoSO}_{4}$.

${ }^{2)}$ Corrected to ash and protein. 
ing the total feces excreted over three consecutive days [13]. In brief, the feces were collected using dustpans and then stored in plastic buckets at room temperature. At the end of each collection day, feces were quantified and mixed. Subsamples of approximately $300 \mathrm{~g}$ of feces (on an as-is basis) were saved each day. The fecal samples were dried in a forcedair oven $\left(55^{\circ} \mathrm{C}\right)$ for $72 \mathrm{~h}$, and ground through a $1-\mathrm{mm}$ screen (Fortinox, Brazil). Furthermore, each period, an individual composite fecal sample from the $3 \mathrm{~d}$ of collection was prepared for each animal based on the DM content of the feces collected on the individual days. The final composite samples represented the $3-\mathrm{d}$ collection of feces on a proportional DM basis.

All animals were slaughtered after $84 \mathrm{~d}$. Steers were fasted for $14 \mathrm{~h}$ before slaughter. The slaughter was performed by stunning using the captive bolt technique followed by jugular vein exsanguination. The digestive tract of each steer was emptied and washed, and each organ was weighed separately. The weight of the heart, lungs, liver, spleen, kidneys, internal fat (fat surrounding kidneys, pelvis, and heart), diaphragm, mesentery, tail, trachea, esophagus, and reproductive tract along the weight of the washed gastrointestinal tract were added to that of the other body parts (head, hide, limbs, and blood) to determine the non-carcass components weight. The non-carcass weight was added to that of the carcass to determine the empty body weight (EBW). Blood samples were collected immediately after slaughter. Samples of blood, organs and viscera, head and limbs, and hide were placed in aluminum trays and freeze-dried (Liotop, LP 510 model, São Carlos, SP, Brazil).

The carcass of each steer was split in to 2 halves along the spine, and then cooled at $-4^{\circ} \mathrm{C}$ for $24 \mathrm{~h}$. After $24 \mathrm{~h}$, the carcass halves were weighed. The 9 th to 11 th rib section was obtained from the left half, as recommended by HH46 [7], and subsequently dissected into bone, fat and muscle tissues. The rest of the left carcass was completely dissected into bone, muscle, and fat tissues, and the 9th to 11th rib section was summed, to obtain the full carcass composition. Dissected samples were weighed, individually ground, packed in aluminum trays, and freeze-dried (Liotop, LP 510 model, Brazil).

All lyophilized samples from the steer's body were ground in a Wiley mill (Fortinox, Brazil) using liquid N. Four subsamples per steer, named "carcass", "non-carcass", "muscle plus fat-rib section", and "bones-rib section" were taken for further determination of the chemical composition. The carcass sample was comprised of the lyophilized samples of bone and muscle plus fat from the carcass. The non-carcass sample was comprised of blood, head and limbs, organs and viscera, and hide. The muscle plus fat-rib section was comprised of muscle and fat from the 9th to 11th rib section, and the bones-rib section contained the bone sample from the 9th to 11th rib section.

\section{Laboratory analysis and calculations}

Individual feed ingredients and feces were analyzed for DM, organic matter (OM), CP, and ether extract (EE) according to the AOAC $[14,15]$. The quantification of neutral detergent fiber (NDF) was performed without the addition of sodium sulfite, but with the addition of thermostable $\alpha$-amylase to neutral detergent (Ankom Tech. Corp., Fairport, NY, USA). The NDF concentrations were corrected for ash [16] and residual $\mathrm{N}$ compounds [17]. The non-fiber carbohydrates were calculated as proposed by Detmann and Valadares Filho [18]. The TDN of the diet was estimated by the sum of digestible nutrients as proposed by NRC [19].

Digestible energy (DE) intake was obtained by multiplying digestible nutrients by their respective energy values [19]. The metabolizable energy intake (MEI) was estimated as $82 \% \mathrm{DE}$ [20]. The metabolizable protein intake (MPI) was obtained by adding the true digestible microbial CP (TDM$\mathrm{CP}$ ) and the digestible RUP (DRUP) intake. The microbial CP (MCP) was calculated as proposed by Valadares Filho et al [2]. In addition, we assumed that the MCP is composed of $80 \%$ of AA and that these AA have an $80 \%$ digestibility [19]. The DRUP intake was estimated based on the difference between CP intake and MCP and multiplied by its intestinal digestibility (80\%) [19].

Carcass, non-carcass, muscle plus fat-rib section, and bones-rib section samples were analyzed for DM [14], and $\mathrm{CP}$ and EE content [21]. The relationship between the shrunk BW (SBW) and EBW was calculated to convert SBW to EBW, while the relationship between the ADG and empty body gain (EBG) was calculated to convert ADG to EBG.

Whole-body energy content (EC) of each steer was obtained from the whole-body content for $\mathrm{CP}$ and fat by using their caloric equivalent [22]. The whole-body retained energy (RE) was calculated as the difference between the final and initial EC of each steer. Heat production (HP) was estimated as the difference between MEI and EC. Then, the net energy requirement for maintenance $\left(\mathrm{NE}_{\mathrm{M}}\right)$ was estimated to be the intercept $\left(\beta_{0}\right)$ of the exponential non-linear regression between HP and MEI [4]:

$$
\mathrm{HP}\left(\mathrm{Mcal} / \mathrm{EBW}^{0.75} / \mathrm{d}\right)=\beta 0 \times \mathrm{e}^{(\beta 1 \times \mathrm{MEI})},
$$

where HP (Mcal/EBW $\left.{ }^{0.75} / \mathrm{d}\right)$, MEI $\left(\mathrm{Mcal} / \mathrm{EBW}^{0.75} / \mathrm{d}\right), \beta 0$ and $\beta 1=$ regression parameters; and $\mathrm{e}=$ the Euler number (2.718281). Also, the $\mathrm{ME}$ requirement for maintenance $\left(\mathrm{ME}_{\mathrm{M}}\right.$, $\mathrm{Mcal} / \mathrm{EBW}^{0.75} / \mathrm{d}$ ) was estimated by the iterative method, with $\mathrm{ME}_{\mathrm{M}}$ considered to be the value where MEI equals HP [2]. The efficiency of utilization of $\mathrm{ME}_{\mathrm{M}}\left(\mathrm{k}_{\mathrm{M}}\right)$ was calculated as the ratio between the $\mathrm{NE}_{\mathrm{M}}$ and $\mathrm{ME}_{\mathrm{M}}$ [2].

The EC as a function of EBW of the animals, was estimated according to the exponential model [22]: 


$$
\mathrm{EC}=\beta 0 \times \mathrm{EBW}^{\beta 1}
$$

The net energy requirement for gain $\left(\mathrm{NE}_{\mathrm{G}}\right)$ was obtained by the derivative of the equation above [22]:

$$
\mathrm{NE}_{\mathrm{G}}=\beta 0 \times \beta 1 \times \mathrm{EBW}^{(\beta 1-1)},
$$

where $\mathrm{NE}_{\mathrm{G}}(\mathrm{Mcal} / \mathrm{kg}$ of EBG), EBW $(\mathrm{kg})$. The efficiency of utilization of $\mathrm{ME}_{\mathrm{G}}\left(\mathrm{k}_{\mathrm{G}}\right)$ was estimated to be the slope ( $\left.\beta 1\right)$ of the linear regression between RE and MEI:

$$
\mathrm{RE}\left(\mathrm{Mcal} / \mathrm{EBW}^{0.75} / \mathrm{d}\right)=\beta 1 \times \mathrm{MEI}+\beta 0,
$$

where RE (Mcal/EBW $\left.{ }^{0.75} / \mathrm{d}\right)$, MEI (Mcal/EBW $\left.{ }^{0.75} / \mathrm{d}\right)$. The metabolizable energy requirement for gain $\left(\mathrm{ME}_{\mathrm{G}}\right.$, Mcal/ $\mathrm{EBW}^{0.75} / \mathrm{d}$ ) was calculated by dividing the $\mathrm{NE}_{\mathrm{G}}$ by $\mathrm{k}_{\mathrm{G}}$ [2] .

The metabolizable protein requirement for maintenance $\left(\mathrm{MP}_{\mathrm{M}}\right)$ was estimated to be the intercept $(\beta 0)$ of the linear regression between MPI and EBG divided by average metabolic EBW $\left(\mathrm{EBW}^{0.75}\right)$ [2], as follows:

$$
\mathrm{MPI}=\beta 1 \times \mathrm{EBG}+\beta 0,
$$

where MPI = metabolizable protein intake $(\mathrm{g} / \mathrm{d}), \mathrm{EBG}(\mathrm{kg} / \mathrm{d})$, and $\beta 0$ and $\beta 1=$ regression parameters.

To calculate the net protein requirement $\left(\mathrm{NP}_{\mathrm{G}}\right)$, we adjusted the model:

$$
\mathrm{NP}_{\mathrm{G}}=\beta 1 \times \mathrm{EBG}+\beta 2 \times \mathrm{RE},
$$

where $\mathrm{NP}_{\mathrm{G}}=$ net protein requirement for gain $(\mathrm{g} / \mathrm{d}), \mathrm{EBG}=$ empty body gain $(\mathrm{kg} / \mathrm{d}), \mathrm{RE}=$ retained energy $(\mathrm{Mcal} / \mathrm{d})$, and $\beta 1$ and $\beta 2=$ regression parameters. The efficiency of metabolizable protein utilization for gain $\left(\mathrm{k}_{\mathrm{PG}}\right)$ was estimated to be the slope $(\beta 1)$ of the equation:

$$
\mathrm{RP}=\beta 1 \times \mathrm{MPI}+\beta 0,
$$

where $\mathrm{RP}=$ whole-body retained protein $\left(\mathrm{g} / \mathrm{EBW}^{0.75} / \mathrm{d}\right)$, MPI $=$ metabolizable protein intake $\left(\mathrm{g} / \mathrm{EBW}^{0.75} / \mathrm{d}\right)$, and $\beta 0$ and $\beta 1$ $=$ regression parameters.

\section{Evaluated equations}

The descriptive statistics of the variables used to estimate the

\begin{tabular}{|c|c|c|c|c|}
\hline Item & Mean & SD & Maximum & Minimum \\
\hline Empty body weight (kg) & 365 & 67.1 & 530 & 196 \\
\hline Organs and viscera (\% EBW) & 18.0 & 2.08 & 22.0 & 12.6 \\
\hline Visceral fat (\% EBW) & 6.28 & 2.20 & 9.81 & 0.72 \\
\hline 9th to 11 th rib section crude protein (\%) & 16.7 & 1.88 & 19.2 & 11.4 \\
\hline 9th to 11 th rib section ether extract (\%) & 22.4 & 7.34 & 35.8 & 6.72 \\
\hline 9th to 11 th rib section water (\%) & 56.7 & 6.91 & 77.3 & 42.62 \\
\hline
\end{tabular}
carcass and empty body chemical composition are presented in Table 2. The equations developed CS16 [12] were used to estimate carcass and empty body chemical composition using the 9th to 11th rib section (Table 3). The equations developed

Table 2. Variable description used to estimate carcass and empty body chemical composition of Holstein $\times$ Zebu steers $(n=33)$

EBW, empty body weight.

Table 3. Equations used to estimate carcass and empty body chemical composition of Holstein $\times$ Zebu steers

\begin{tabular}{ll}
\hline Item & Equations \\
\hline Carcass chemical composition & \\
Hankins and Howe [7] & $\mathrm{CP}_{\text {carc }}=5.98+0.66 \times \mathrm{CP}_{\mathrm{RS}}$ \\
& $\mathrm{EE}_{\text {carc }}=2.82+0.77 \times \mathrm{EE}_{\mathrm{RS}}$ \\
& $\mathrm{W}_{\text {carc }}=14.90+0.78 \times \mathrm{W}_{\mathrm{RS}}$ \\
& $\mathrm{CP}_{\text {carc }}=18.38+0.16 \times \mathrm{CP}_{\mathrm{RS}}-0.20 \times \mathrm{OV}$ \\
& $\mathrm{EE}_{\text {carc }}=4.54+0.48 \times \mathrm{EE}_{\mathrm{RS}}+0.12 \times \mathrm{OV}$ \\
& $\mathrm{W}_{\text {carc }}=55.67-0.21 \times \mathrm{W}_{\mathrm{RS}}-0.021 \times \mathrm{EBW}$ \\
& $\mathrm{CP}_{\mathrm{EBW}}=19.92+0.086 \times \mathrm{CP}_{\mathrm{RS}}-0.19 \times \mathrm{OV}$ \\
Costa e Silva et al [12] & $\mathrm{EE}_{\mathrm{EBW}}=3.53+0.34 \times \mathrm{EE}_{\mathrm{RS}}+0.80 \times \mathrm{VF}+0.10 \times \mathrm{OV}$ \\
& $\mathrm{W}_{\mathrm{EBW}}=53.02+0.17 \times \mathrm{W}_{\mathrm{RS}}-1.28 \times \mathrm{VF}+0.27 \times \mathrm{OV}$ \\
\hline
\end{tabular}

$\mathrm{CP}_{\text {carc }}$ crude protein in the carcass (\%); $\mathrm{CP}_{\mathrm{RS}}$, crude protein in the 9th-11th rib section (\%); $\mathrm{EE}_{\text {carc }}$, ether extract in the carcass (\%); $\mathrm{EE}_{\mathrm{RS}}$, ether extract in the 9th-11th rib section (\%); $W_{\text {carc, }}$ water in the carcass (\%); $W_{R S}$, water in the 9 th-11th rib section (\%); EBW, empty body weight (kg); OV, percentage of organs and viscera in the EBW (\% EBW); VF, percentage of mesenteric fat plus renal, pelvic, and cardiac fat in the EBW (\% EBW); $C P_{N C}$, Crude protein in the non-car$\operatorname{cass}(\mathrm{kg}) ; \mathrm{E}_{\mathrm{NC}}$, ether extract in the non-carcass $(\mathrm{kg}) ; \mathrm{W}_{\mathrm{NC}}$, water in the carcass $(\mathrm{kg}) ; \mathrm{CP}_{\mathrm{EBW}}$, crude protein in the empty body $(\%)$; $\mathrm{EE}_{\mathrm{EBW}}$, ether extract in the empty body (\%); and $\mathrm{W}_{\mathrm{EBW}}$, water in the empty body (\%). 
HH46 [7] were used to estimate carcass chemical composition using the 9th to 11th rib section only. It is important to highlight that the present data was independent of those used to develop the predictive equations from HH46 [7] and CS16 [12].

\section{Statistical analysis}

The relationship between the SBW and EBW and the ADG and EBG, and data on energy and protein requirements were analyzed as linear and nonlinear models built through the REG and NLIN procedures of SAS (version 9.4, SAS Inst. Inc.; Cary, NC, USA), respectively, in which the nonlinear model was adjusted with the Gauss-Newton method.

The body components estimated by HH46 [7] and CS16 [12] equations were compared with the observed values using the following regression model: $y=\beta_{0}+\beta_{1} \times x$, where $x=$ predicted values; $y=$ observed values; $\beta_{0}$ and $\beta_{1}=$ intercept and slope, respectively. The regression was evaluated according to the following statistical hypothesis: $\mathrm{H}_{0}: \beta_{0}=0$ and $\mathrm{H}_{0}$ : $\beta_{1}=1$, and $\mathrm{H}_{\mathrm{a}}$ : not $\mathrm{H}_{0}$. If the null hypotheses were not rejected, it could be concluded that the equations accurately and precisely estimate the body components of Holstein $\times \mathrm{Zebu}$ steers. Slope and intercept were separately evaluated to observe possible errors in the equations.

Estimates were also evaluated using the mean square error of prediction (MSEP) and its components [23]:

$$
\begin{aligned}
& \mathrm{MSEP}=\mathrm{SB}+\mathrm{MaF}+\mathrm{MoF}=1 / n \sum_{i=1}\left(x_{i}-y_{i}\right)^{2} \\
& \mathrm{SB}=\left(x_{i}-y_{i}\right)^{2} \\
& \mathrm{MaF}=\left(s_{x}-s_{y}\right)^{2} \\
& \mathrm{Mof}=2 s_{x} s_{y}(1-r)
\end{aligned}
$$

where $x$ are predicted values; $y$ are observed values; MSEP is the mean squared error of prediction; SB is the squared bias; $\mathrm{MoF}$ is the component relative to the model of random fluctuation; $\mathrm{MaF}$ is the component relative to the magnitude of random fluctuation; $s_{x}$ and $s_{y}$ are the standard deviations of the predicted and observed values, respectively, and $r$ is the Pearson linear correlation coefficient between the predicted and observed values. The prediction of efficiency was determined by estimating the correlation and concordance coefficient or reproducibility index (CCC) as described by Tedeschi [24]. Values of CCC below 0.4, between 0.4 and 0.7 , and above 0.7 were considered low, medium, and high, respectively. All calculations were obtained using the Model Evaluation System (MES) [24]. For comparisons, the level of 0.05 was established as the critical level of probability for type I error.

\section{RESULTS AND DISCUSSION}

\section{Energy and protein requirements}

The average ratio between EBW and SBW and EBG and ADG observed in this experiment were 0.88 and 0.93 , respectively ( $\mathrm{R}^{2}$ of 0.98 and 0.97 , respectively). The relationship between $\mathrm{HP}$ and MEI was described by the equation:

$$
\mathrm{HP}=0.083 \times e^{\left(3.2917_{( \pm 0.1222)} \times M E I\right)} .
$$

Thus, the $\mathrm{NE}_{\mathrm{M}}$ was $0.083 \mathrm{Mcal} / \mathrm{EBW}^{0.75} / \mathrm{d}$, while $\mathrm{ME}_{\mathrm{M}}$ was $0.125 \mathrm{Mcal} / \mathrm{EBW}^{0.75} / \mathrm{d}$ for Holstein $\times$ Zebu steers. Therefore, the $\mathrm{k}_{\mathrm{M}}$ was 0.66 . The $\mathrm{NE}_{\mathrm{G}}$ can be estimated with the equation:

$$
\begin{aligned}
& \mathrm{NE}_{\mathrm{G}}(\mathrm{Mcal} / \mathrm{kg} \mathrm{EBG}) \\
& =0.2973_{( \pm 0.1212)} \times E B W^{0.4336_{( \pm 0.1002)} .}
\end{aligned}
$$

The $\mathrm{k}_{\mathrm{G}}$ was 0.35 , and this value was obtained based on the slope of the linear relationship between RE and MEI.

The $\mathrm{MP}_{\mathrm{M}}$ was $4.40 \mathrm{~g} / \mathrm{EBW}^{0.75}$, and this value was obtained based on a linear regression between MPI and EBG divided by the average metabolic EBW. The $\mathrm{NP}_{\mathrm{G}}$ were estimated from the model:

$$
\mathrm{NP}_{\mathrm{G}}(\mathrm{g} / \mathrm{d})=183.6_{( \pm 22.5333)} \times \mathrm{EBG}-2.0693_{( \pm 4.7254)} \times \mathrm{RE} .
$$

The $\mathrm{k}_{\mathrm{PG}}$ was 0.39 , and this value was obtained based on the slope of the linear regression between RP and MPI.

The male dairy cattle (Holstein and Holstein crossbreeds) play important participation in feedlots in Brazil and the USA [3-5]. However, although it is acknowledged that dairy and beef cattle exhibit differences regarding their nutritional requirements [1,2], most of nutritionists use some version beef cattle NRC as source of information on nutrient requirements to formulate diets $[3,6]$. In this context, we compared energy and protein requirements estimated by equations proposed in this study with the values estimated by the last update of beef cattle NRC (NASEM) [1], which have maintained the same recommendations of the previous version [20] for energy and protein requirements.

Considering a steer with $416 \mathrm{~kg}$ of SBW, EBW of 365, shrunk body gain of $1.38 \mathrm{~kg} / \mathrm{d}, \mathrm{EBG}$ of $1.29 \mathrm{~kg} / \mathrm{d}$ (the average of the steers in this study), and equivalent EBW (EQEBW) of $355 \mathrm{~kg}$ (EQEBW was calculated considering the BW at maturity of $532 \mathrm{~kg}$ and standard reference weight of 517 [2]), the values calculated by our equations and the same values estimated with NASEM [1] equations were: 6.93 and 7.09 $\mathrm{Mcal} / \mathrm{d}$ for $\mathrm{NE}_{\mathrm{M}}, 4.95$ and $6.86 \mathrm{Mcal} / \mathrm{d}$ for $\mathrm{NE}_{\mathrm{G}}, 367$ and 350 $\mathrm{g} / \mathrm{d}$ for $\mathrm{MP}_{\mathrm{M}}$, and 227 and $168 \mathrm{~g} / \mathrm{d}$ for $\mathrm{NP}_{\mathrm{G}}$. In comparison to the values calculated by the equations proposed in this study, the $\mathrm{NE}_{\mathrm{M}}$ and $\mathrm{NE}_{\mathrm{G}}$ estimated by NASEM [1] were approxi- 
mately 0.16 and $1.91 \mathrm{Mcal} / \mathrm{d}$ greater, respectively. However, the $\mathrm{MP}_{\mathrm{M}}$ and $\mathrm{NP}_{\mathrm{G}}$ estimated by NASEM [1] were approximately 17 and $59 \mathrm{~g} / \mathrm{d}$ below the value calculated by equations developed in the current study.

The most substantial differences between the requirements estimated by the equations proposed in this study and NASEM [1] are regarding $\mathrm{NE}_{\mathrm{G}}$ and $\mathrm{NP}_{\mathrm{G}}$. The composition of $\mathrm{EBG}$ is the main determinant for estimating the nutrient requirements for BW gain, and it depends on the physiological maturity of the cattle, which is affected by sex and breed [25]. Differently from our database, the equations recommended by NASEM [1] are derived from studies based on body composition of Bos taurus beef purebreds and their crossbreds. Differences in maturity degree of the different genetic groups reflect different body composition in animals with the same BW [2]. Thus, for animals with the same BW and weight gain rate, which is the case of the example above, higher energetic and lower protein concentrations are expected in the gain, and consequently greater energy and lower protein requirements for gain in animals from genetic groups with lower weight at maturity (medium-frame steers; i.e. beef steers), compared with genetic groups with later maturity (large-frame steers; i.e. dairy steers) [2]. Therefore, the differences observed between the nutrient requirements obtained in the current study and those values estimated by NASEM [1] might be due cattle genetics. Nevertheless, it is important to highlight that the dietary management applied to animals in the current study may also have influenced the nutrient requirement estimations.

\section{Carcass chemical composition}

The HH46 [7] equation did not correctly estimate carcass chemical content of CP and EE (Table 4) because it rejected the null hypothesis of a respective intercept and slope equal to 0 and $1(\mathrm{p}<0.05)$. Comparing the maximum values estimated with the observed values, HH46 [7] equations overestimated CP and EE by $8.60 \%$ and $16.6 \%$, respectively. Good precision and accuracy were observed when estimating water carcass content with the HH46 [7] equation, as CCC was close to 1 ; and it did not reject the null hypothesis of a respective intercept and slope equals to 0 and 1 ( $p>0.05)$. However, CS16 [12] equations had problems of adjustment for carcass water content according to the slope of regression analysis $(\mathrm{p}<0.05)$, indicating poor accuracy.

The CS16 [12] equations accurately and precisely estimated $\mathrm{CP}$ and $\mathrm{EE}$ in carcasses, as the null hypothesis of a respective intercept and slope equal to 0 and 1 ( $p>0.05)$ were not rejected; and CCC was close to 1 (CCC of 0.91 and 0.91 for $\mathrm{CP}$ and $\mathrm{EE}$, respectively). The accuracy of prediction equations tends to decrease when they are used to estimate carcass

Table 4. Mean $(\mathrm{kg})$ and descriptive statistics for relationship among the observed and predicted values to carcass and empty body chemical composition

\begin{tabular}{|c|c|c|c|c|c|c|c|c|c|c|c|c|c|c|c|}
\hline \multirow{3}{*}{ Item } & \multicolumn{9}{|c|}{ Carcass } & \multicolumn{6}{|c|}{ Empty body } \\
\hline & \multicolumn{3}{|c|}{ Crude protein } & \multicolumn{3}{|c|}{ Ether extract } & \multicolumn{3}{|c|}{ Water } & \multicolumn{2}{|c|}{ Crude protein } & \multicolumn{2}{|c|}{ Ether extract } & \multicolumn{2}{|c|}{ Water } \\
\hline & Obs. ${ }^{1)}$ & $\mathrm{HH}_{46}{ }^{2)}$ & $\mathrm{CS} 16^{2)}$ & Obs. ${ }^{1)}$ & $\mathrm{HH} 46^{2)}$ & $\mathrm{CS} 6^{2)}$ & Obs. ${ }^{1)}$ & $\mathrm{HH}_{46}^{2}$ & $\mathrm{CS} 16^{2)}$ & Obs. ${ }^{1)}$ & $\mathrm{CS}_{16}{ }^{2)}$ & Obs. ${ }^{1)}$ & $\mathrm{CS}{ }^{2)}$ & Obs. ${ }^{1)}$ & $\mathrm{CS}_{16}{ }^{2)}$ \\
\hline Mean & 35.4 & 36.3 & 37 & 39.8 & 44.6 & 38.5 & 130 & 125.1 & 127 & 58.6 & 64 & 69.4 & 67.3 & 215 & 213 \\
\hline SD & 5.68 & 6.96 & 6.04 & 11.7 & 16.2 & 12.1 & 20.3 & 18.8 & 18.3 & 10.3 & 10.3 & 22.7 & 23.1 & 31.1 & 29.7 \\
\hline Maximum & 43.5 & 47.6 & 44.9 & 62.6 & 73.8 & 59.8 & 155 & 159 & 152 & 74.1 & 78.8 & 112 & 111 & 258 & 256 \\
\hline Minimum & 22.7 & 18.1 & 21.7 & 14.1 & 11.3 & 13.1 & 72 & 74.7 & 77.6 & 34.9 & 37.4 & 22.8 & 19.4 & 122 & 129 \\
\hline $\mathrm{R}^{2}$ & - & 0.9 & 0.94 & - & 0.88 & 0.91 & - & 0.92 & 0.98 & - & 0.97 & - & 0.96 & - & 0.99 \\
\hline $\mathrm{CCC}$ & - & 0.88 & 0.91 & - & 0.79 & 0.91 & - & 0.89 & 0.97 & - & 0.85 & - & 0.96 & - & 0.98 \\
\hline \multicolumn{16}{|l|}{ Regression } \\
\hline \multicolumn{16}{|l|}{ Intercept } \\
\hline Estimate & - & 8.59 & 2.49 & - & 11.4 & 5.57 & - & 5.44 & -9.23 & - & -3.33 & - & 5.8 & - & -4.76 \\
\hline Standard error & - & 2.386 & 2.151 & - & 2.92 & 2.895 & - & 10.088 & 5.263 & - & 2.93 & - & 3.479 & - & 6.147 \\
\hline$p$-value ${ }^{3)}$ & - & 0.001 & 0.257 & & $<0.001$ & 0.064 & - & 0.593 & 0.09 & - & 0.265 & - & 0.106 & - & 0.445 \\
\hline \multicolumn{16}{|l|}{ Slope } \\
\hline Estimate & - & 0.74 & 0.89 & - & 0.64 & 0.89 & - & 0.99 & 1.09 & - & 0.97 & - & 0.94 & - & 1.03 \\
\hline Standard error & - & 0.065 & 0.057 & - & 0.062 & 0.072 & - & 0.08 & 0.04 & - & 0.045 & - & 0.049 & - & 0.029 \\
\hline$p$-value ${ }^{4)}$ & - & $<0.001$ & 0.06 & - & $<0.001$ & 0.127 & - & 0.923 & 0.036 & - & 0.484 & - & 0.264 & - & 0.248 \\
\hline MSEP & - & 9.73 & 6.59 & - & 86.5 & 25.9 & - & 85.2 & 23.8 & - & 35.3 & - & 44.4 & - & 27.8 \\
\hline SB & - & 0.84 & 2.77 & - & 22.8 & 1.53 & - & 20 & 4.9 & - & 28.9 & - & 4.2 & - & 5.85 \\
\hline $\mathrm{MaF}$ & - & 3.22 & 0.44 & - & 33.6 & 1.79 & - & 0.02 & 2.61 & - & 0.1 & - & 1.61 & - & 0.97 \\
\hline MoF & - & 5.68 & 3.37 & - & 30.1 & 22.6 & - & 65.2 & 16.3 & - & 6.26 & - & 38.6 & - & 21 \\
\hline
\end{tabular}

SD, standard deviation; CCC, correlation and concordance coefficient; MSEP, mean square error of prediction; SB, squared bias; MaF, magnitude of random

fluctuation; MoF, model of random fluctuation.

1) Obs, observed values.

2) $\mathrm{HH} 46$, equations proposed by Hankins and Howe [7]; CS16, equations proposed by Costa e Silva et al [12].

3) $\mathrm{Ho}: \beta 0=0$.

4) $\mathrm{Ho}: \beta 1=1$. 
composition of animals from genetic groups different from the ones used to generate the equation in the first place [26, 27]. The HH46 [7] equations were developed based on carcass chemical composition of Bos taurus beef purebreds and their crossbreds. At the same BW, beef carcasses (Angus) have greater soft tissue to bone ratio, and proportionally more fat than dairy carcasses (Holstein) [28]. These differences are likely because genetic selection in dairy cattle has been focused on milk production rather than tissues deposition. Therefore, the presence of the Holstein breed in the genotype of the animals of the current study, may have resulted in a different growth and conformation pattern when compared to breeds selected for beef production and their crossbreds. Similar to our results, Nour and Thonney [29] pointed out that differences among breed types must be considered for greater accuracy and precision of prediction when using HH46 [7] equations to predict carcass composition of Angus and Holstein steers. Nevertheless, it is important to highlight that the dietary management applied to animals in the current study may also have influenced the body composition obtained.

The CS16 [12] equations were developed using a database composed by animals Holstein $\times$ Zebu, which probably resulted in the best goodness of fit for $\mathrm{CP}$ and $\mathrm{EE}$ content in carcass among the equations evaluated. Therefore, CS16 [12] equations are more appropriate to predict $\mathrm{CP}$ and $\mathrm{EE}$, whereas HH46 [7] equations better explained the variation in carcass water content of Holstein $\times$ Zebu steers.

\section{Empty body chemical composition}

The CS16 [12] equations did not reject the null hypothesis of a respective intercept and slope equal of 0 and 1 ( $p>0.05)$, and presented high $\mathrm{R}^{2}$ ( $\mathrm{R}^{2}$ of $0.97,0.96$, and 0.99 for $\mathrm{CP}, \mathrm{EE}$, and water, respectively) and CCC (CCC of $0.85,0.96$, and 0.98 for $\mathrm{CP}, \mathrm{EE}$, and water, respectively) values for all chemical contents evaluated (Table 4).

Moreover, the prediction errors for EE and water empty body contents were mostly (more than 75\% of MSEP) associated with random errors, rather than central tendency, and due to linear regression or systematic bias. However, most of prediction error for CP in the empty body (more than $80 \%$ of MSEP) was associated with the SB.

The CS16 [12] equations are part of the suggested equations in the 3rd edition of Nutrient Requirements of Zebu and Crossbred Cattle [2] for estimating body composition of Zebu and crossbred cattle. The CS16 [12] equations were developed after authors verified that equations generated based on a database composed by Zebu cattle (mainly Nellore) and their crosses with Bos taurus beef breeds (Angus or Simmental) [30] did not correctly estimate body composition of crossbred dairy cattle. However, until the present study, CS16 [12] equations had not been evaluated with an independent database.
In the current study, CS16 [12] equations accurately estimated all chemical components of empty body. However, reduced goodness of fit was observed when predicting $\mathrm{CP}$ content. The CS16 [12] developed equations using body composition data from crossbred dairy cattle, which were composed by 80 bulls, 56 steers, and 44 heifers. The greater proportion of bulls in the database of CS16 [12] could explain the reduced goodness of fit in predicting empty body $\mathrm{CP}$ in the current study, as bulls usually have greater $\mathrm{CP}$ content and accretion rates than steers [25]. However, when predicting empty body CP sex was not shown to be significant [12].

In summary, the $\mathrm{NE}_{\mathrm{M}}$ and $\mathrm{MP}_{\mathrm{M}}$ of Holstein $\times$ Zebu steers were $0.083 \mathrm{Mcal} / \mathrm{EBW}^{0.75} / \mathrm{d}$ and $4.40 \mathrm{~g} / \mathrm{EBW}^{0.75}$, respectively. The $\mathrm{NE}_{\mathrm{G}}$ and $\mathrm{NP}_{\mathrm{G}}$ can be estimated with the following equations:

$$
\begin{aligned}
& \mathrm{NE}_{\mathrm{G}}(\mathrm{Mcal} / \mathrm{d})=0.2973 \times \mathrm{EBW}^{0.4336} \text { and } \\
& \mathrm{NP}_{\mathrm{G}}(\mathrm{g} / \mathrm{d})=183.6 \times \mathrm{EBG}-2.0693 \times \mathrm{RE} .
\end{aligned}
$$

Moreover, our results suggested that there may be differences between the $\mathrm{NE}_{\mathrm{G}}$ and $\mathrm{NP}_{\mathrm{G}}$ of beef and dairy crossbred steers. Thus, the equations described above may be used to calculate the nutrient requirements of Holstein $\times$ Zebu steers instead of using recommendations based on values from beef cattle.

The $\mathrm{CP}$ and EE chemical contents in carcass, and all chemical components in the empty body were precisely and accurately estimated by CS16 [12] equations. However, water content in carcass was better predicted by HH46 [7] equation. Therefore, the equations proposed by CS16 [12] were the best estimator for $\mathrm{CP}$ and $\mathrm{EE}$ in carcass of crossbred dairy steers, whereas water in carcass is better estimated using equations proposed by HH46 [7]. The equations proposed by CS16 [12] can be used to estimate all chemical components in the empty body.

\section{CONFLICT OF INTEREST}

We certify that there is no conflict of interest with any financial organization regarding the material discussed in the manuscript.

\section{ACKNOWLEDGEMENTS}

This study was supported by CNPQ (Brazil), CAPES (Brazil), FAPEMIG (Brazil), and INCT - CA (Brazil). Thanks are also extended to Department of Animal Science of Pennsylvania State University for the collaboration on the preparation of this manuscript. 


\section{REFERENCES}

1. National Academies of Sciences, Engineering, and Medicine. Nutrient requirements of beef cattle. 8th ed. Washington, DC, USA: The National Academies Press; 2016. https://doi. org/10.17226/19014

2. Valadares Filho SC, Costa e Silva LF, Gionbelli MP, et al. Nutrient requirements of Zebu and crossbred cattle (BRCORTE). 3rd ed. Visconde do Rio Branco, MG, Brazil: Suprema Gráfica Ltda; 2016. https://doi.org/10.5935/97885-8179-111-1.2016B002

3. Samuelson KL, Hubbert ME, Galyean ML, Löest CA. Nutritional recommendations of feedlot consulting nutritionists: the 2015 New Mexico State and Texas Tech University survey. J Anim Sci 2016;94:2648-63. https://doi.org/10.2527/jas. 2016-0282

4. Sistema de produção de leite com recria de novilhas em sistemas silvipastoris [Internet]. Juiz de Fora, MG, Brazil: Embrapa Gado de Leite; c2005 [cited 2019 Apr 24]. Available from: https://sistemasdeproducao.cnptia.embrapa.br/Fontes HTML/Leite/LeiteRecriadeNovilhas/index.htm

5. Madalena FE, Peixoto MGCD, Gibson J. Dairy cattle genetics and its applications in Brazil. Livest Res Rural Dev 2012;24: 97.

6. Oliveira CA, Millen DD. Survey of the nutritional recommendations and management practices adopted by feedlot cattle nutritionists in Brazil. Anim Feed Sci Technol 2014;197: 64-75. https://doi.org/10.1016/j.anifeedsci.2014.08.010

7. Hankins OG, Howe PE. Estimation of the composition of beef carcasses and cuts. In: Technical Bulletins No. 926. Washington, DC, USA: USDA; 1946. pp. 1-19.

8. Kraybill HF, Bitter HL, Hankins OG. Body composition of cattle. II. Determination of fat and water content from measurement of body specific gravity. J Appl Physiol 1952;4:57583. https://doi.org/10.1152/jappl.1952.4.7.575

9. De Paula NF, Tedeschi LO, Paulino MF, Fernandes HJ, Fonseca MA. Predicting carcass and body fat composition using biometric measurements of grazing beef cattle. J Anim Sci 2013; 91:3341-51. https://doi.org/10.2527/jas.2012-5233

10.Paulino PVR, Costa MAL, Valadares Filho SC, et al. Validation of the equations proposed by Hankins and Howe for estimating the carcass composition of zebu cattle and development of equations to predict the body composition. Rev Bras Zootec 2005;34:327-39. https://doi.org/10.1590/ S1516- 35982005000100037

11. Marcondes MI, Valadares Filho SC, Paulino PVR, et al. Predicting body and carcass composition using the section between 9th and 11th ribs in Nellore cattle. Rev Bras Zootec 2009; 38:1597-604. https://doi.org/10.1590/S1516-359820 09000800026

12. Costa e Silva LF, Valadares Filho SC, Rotta PP, et al. Prediction of body and carcass composition of beef cattle. In: Valadares
Filho SC, Costa e Silva LF, Gionbelli MP, et al editors. Nutrient requirements of Zebu and crossbred cattle (BR-CORTE). 3rd ed. Visconde do Rio Branco, MG, Brazil: Suprema Gráfica Ltda; 2016. pp. 119-42. https://doi.org/10.5935/978-85-8179111-1.2016B002

13. Costa e Silva LF, Valadares Filho SC, Engle TE, et al. Macrominerals and trace element requirements for beef cattle. PLoS One 2015;10:e0144464. https://doi.org/10.1371/journal.pone. 0144464

14. Latimer GW; AOAC International. Official methods of analysis of AOAC International. 19th ed. Gaithersburg, MD, USA: AOAC International; 2012.

15. Horwitz W, Latimer GW; AOAC International. Official methods of analysis of AOAC International. 18th ed. Gaithersburg, MD, USA: AOAC International; 2006.

16. Mertens DR. Gravimetric determination of amylase-treated neutral detergent fiber in feeds with refluxing in beakers or crucibles: collaborative study. J AOAC Int 2002;85:1217-40.

17.Licitra G, Hernandez TM, Van Soest PJ. Standardization of procedures for nitrogen fractionation of ruminant feeds. Anim Feed Sci Technol 1996;57:347-58. https://doi.org/10.1016/ 0377-8401(95)00837-3

18. Detmann E, Valadares Filho SC. On the estimation of nonfibrous carbohydrates in feeds and diets. Arq Bras Med Vet Zootec 2010;62:980-4. https://doi.org/10.1590/S0102-093520 10000400030

19. Committee on Animal Nutrition, National Research Council. Nutrient requirements of dairy cattle. 7th ed. Washington, DC, USA: National Academies Press; 2001.

20. Committee on Animal Nutrition, National Research Council. Nutrient requirements of beef cattle. 7th ed. Washington, DC, USA: National Academies Press; 1996.

21. AOAC International. Official methods of analysis of the AOAC International. 15th ed. Arlington, VA, USA: AOAC International; 1990.

22. Agricultural Research Council. The nutrient requirements of ruminant livestock. Slough, UK: Commonwealth Agricultural Bureaux; 1980.

23. Kobayashi K, Salam MU. Comparing simulated and measured values using mean squared deviation and its components. Agron J 2000;92:345-52. https://doi.org/10.2134/agronj2000. 922345x

24. Tedeschi LO. Assessment of the adequacy of mathematical models. Agric Syst 2006;89:225-47. https://doi.org/10.1016/j. agsy.2005.11.004

25. Fortin A, Simpfendorfer S, Reid JT, Ayala HJ, Anrique R, Kertz AF. Effect of level of energy intake and influence of breed and sex on the chemical composition of cattle. J Anim Sci 1980;51:604-14. https://doi.org/10.2527/jas1980.513604x

26. Abraham HC, Carpenter ZL, King GT, Butler OD. Relationships of carcass weight, conformation and carcass measurements and their use in predicting beef carcass cutability. J 
Anim Sci 1968;27:604-10. https://doi.org/10.2527/jas1968. 273604x

27. Kempster AJ. Genetic variation in the carcass characteristics of cattle, sheep and pigs. World Rev Anim Prod 1979;15:9-21.

28. Nour AYM, Thonney ML, Stouffer JR, White WRC. Muscle, fat and bone in serially slaughtered large dairy or small beef cattle fed corn or corn silage diets in one of two locations. J Anim Sci 1981;52:512-521. https://doi.org/10.2527/jas1981. $523512 x$
29. Nour AYM, Thonney ML. Technical note: chemical composition of Angus and Holstein carcasses predicted from rib section composition. J Anim Sci 1994;72:1239-41. https:// doi.org/10.2527/1994.7251239x

30.Marcondes MI, Tedeschi LO, Valadares Filho SC, Chizzotti ML. Prediction of physical and chemical body compositions of purebred and crossbred Nellore cattle using the composition of a rib section. J Anim Sci 2012;90:1280-90. https:/doi.org/ 10.2527/jas.2011-3839 